\title{
Terra, trabalho e capital: questão agrária no Brasil e crítica social
}

Helen Scorsatto Ortiz ${ }^{*}$

Questão agrária, cooperação e agroecologia é uma obra coletiva que reúne textos de 25 autores com formações sólidas e diversas, nas mais destacadas instituições de ensino do país. São pesquisadores, professores, intelectuais militantes e assentados que desenvolveram seus estudos em Ciências Econômicas, Ciências Sociais, Engenharia Agronômica, Engenharia de Alimentos, Geografia, História, Pedagogia e Psicologia Social. A coletânea é organizada pelo trio composto pelo doutor Henrique Tahan Novaes, docente da Faculdade de Filosofia e Ciências - Unesp de Marília - e do Programa de Pós-Graduação em Educação, pela sua ex-orientanda Laís Ribeiro dos Santos, graduada em Pedagogia e mestre em Educação na linha de pesquisa "Políticas educacionais, gestão de sistemas e organizações, trabalho e movimentos sociais", e pelo historiador Ângelo Diogo Mazin, mestrando em Geografia e assentado no Projeto de Assentamento Luiz Beltrame, em Gália, São Paulo.

O livro congrega capítulos de membros dos grupos de pesquisa Organizações
\& Democracia (Unesp, Marília) e Instituto Brasileiro de Estudos Contemporâneos (Ibec, São Paulo), assim como de autores convidados e especialistas. É produto de um projeto mais amplo, financiado pelo Conselho Nacional de Desenvolvimento Científico e Tecnológico (CNPq) e pelo Ministério do Desenvolvimento Agrário, que previu a oferta de um curso técnico em Agroecologia para jovens assentados de São Paulo. O conjunto dos textos trata, sobretudo, da realidade agrária e fundiária brasileira e está dividido em quatro partes: Questão agrária no Brasil; História da cooperação, cooperativismo e associativismo rural; Produção destrutiva e agroecologia; Mundialização, trabalho, gênero e juventude do campo.

\footnotetext{
Doutora em História pela Pontifícia Universidade Católica do Rio Grande do Sul. Professora do Instituto Federal do Rio Grande do Sul, campus Porto Alegre. E-mail: helen.scortiz@gmail.com

Recebido em 01/03/2017 - Aprovado em 30/03/2017 http://dx.doi.org/10.5335/hdtv.17n.2.7499
} 
A primeira parte inicia com um resgate dos elementos fundamentais da contribuição de três autores clássicos - Caio Prado Júnior, Florestan Fernandes e Octávio Ianni - para a análise da questão agrária no Brasil. Situações e problemas que se propuseram a investigar e discutir, décadas atrás, ainda estão presentes no campo brasileiro, com destaque para a concentração fundiária refletindo na submissão dos trabalhadores rurais e em (más) condições do trabalho urbano. Nas palavras de Fabiana Rodrigues, a questão agrária "é definidora da correlação de forças que se estabelece entre capital e trabalho" (2016, p. 21).

Integra, também, a primeira parte do livro um interessante capítulo acerca do agronegócio, destacando a gênese de suas bases e desvendando suas (pseudo)contradições. Há um gritante descompasso entre o discurso hegemônico que apresenta o agronegócio como modelo de desenvolvimento econômico, tecnológico e científico e o fato de que sua sustentação está ligada ao latifúndio, à destruição ambiental, à superexploração do trabalho, ao uso de agrotóxicos e transgênicos, etc. Embora o tema da sustentabilidade e/ou da responsabilidade social e ambiental tenha virado lema para as empresas do setor, não encontra correspondência na prática. Os interesses do agronegócio encontram defesa também em suas organizações de classe, na relação com as universidades públicas (pesquisas encomendadas) e com o Estado, que lhes distribuiu recursos em detrimento da pequena agricultura e dos verdadeiros produtores de alimento no país. Nesse processo de produção/exportação de matérias-primas, ontem como hoje, as elites agrárias brasileiras subordinam os interesses nacionais à lógica do capital estrangeiro.

Nos dois textos que seguem e finalizam o primeiro bloco da obra, os autores discutem, de forma crítica, a luta pela terra, a centralidade histórica da questão agrária em se tratando de conflitos sociais no Brasil, o atual desenvolvimento das forças capitalistas e a necessidade e o caráter da reforma agrária. Este último tema está presente no cenário brasileiro desde 1946, quando foi proposto na Assembleia Constituinte pelo então senador Luís Carlos Prestes (PCB). Passados setenta anos, no contexto do agronegócio e do capital financeiro na agricultura, Miguel Stedile entende que, para o Movimento dos Trabalhadores Rurais Sem Terra (MST), a luta pela reforma agrária clássica se esgotou. Não basta apenas a distribuição de terras, mas é necessária uma reforma agrária popular - advinda da luta camponesa em associação com os trabalhadores urbanos -, baseada na produção agroecológica, que produza alimentos saudáveis, sem uso de agrotóxicos.

Já para Ângelo Mazin, dado o grau de desenvolvimento do capitalismo contemporâneo, as reflexões acerca da reforma agrária partem do seguinte questionamento: será que sua realização só é possível com a superação do atual modo de produção? No tocante à convivência entre latifúndio e capitalismo, o autor declara que nunca estiveram em contradição no Brasil. Para ele, a reforma agrária no país não é uma necessidade do sistema, mas uma luta anticapitalista. Segundo Mazin, a "tendência histórica do capitalismo é a expropriação dos meios de produção" (2016, p. 87), sendo assim, a terra, 
como fonte de produção de riquezas, tende a sofrer processos de concentração. Além da realidade da concentração fundiária em si, ele nos lembra que, atualmente, milhões de hectares de terras brasileiras são controlados pelo capital estrangeiro. De outro lado, na luta pela reforma agrária, há os assentamentos - como territórios de possibilidades.

A parte dois do livro contém capítulos a respeito da história da cooperação, do cooperativismo e associativismo rural e um capítulo sobre a sociedade comunista na visão de Marx e Engels, este último escrito por Newton Ferreira da Silva e Paulo Alves de Lima Filho. Fica clara a ideia de que os autores percebem o comunismo não como utopia, mas como possibilidade real de nova organização social, tendo muito a proporcionar à humanidade.

Já o texto de Pedro Ivan Christoffolli apresenta alguns elementos introdutórios para a história do cooperativismo e associativismo rural no Brasil. Ao partir de concepção ampla de cooperação, pretende retomar experiências históricas de associativismo no trabalho na agricultura brasileira, alicerçado em movimentos de trabalhadores e povos indígenas. Em se tratando de experiências mais recentes, exibe o caso do MST. Segundo o autor, esse movimento articulou o cooperativismo e o associativismo sob o conceito de cooperação agrícola ou cooperação na agricultura. O desenvolvimento da cooperação no MST se deu por etapas, tendo, primeiramente, como foco central a conquista da terra e a formação de associações (pequenas e informais), dada a resistência às cooperativas. Na etapa seguinte, constituem-se grupos e assentamentos coletivos, estrutura- dos em torno das cooperativas de produção agropecuária. Na terceira etapa, os coletivos perdem importância e as cooperativas de comercialização e prestação de serviços tornam-se o centro dos planos de organização dos assentamentos. A fase posterior é de duros golpes para as cooperativas ligadas ao MST, culminando no fechamento ou na imobilização de muitas delas. Ainda conforme o autor, a etapa atual caracteriza-se pelos programas públicos de apoio ao acesso a mercados, com importante reserva para a agricultura familiar. O desafio está em aumentar o número de famílias assentadas que acessam esses programas, assim como rediscutir políticas públicas de desenvolvimento rural que promovam o associativismo e a sustentabilidade.

Ao trazer elementos sobre a história do trabalho associado, Candido Vieitez e Neusa Maria Dal Ri entendem que os trabalhadores é que são os verdadeiros produtores - ideia inversa ao pensamento oficial, que "supõe que o produtor é o burguês e que os trabalhadores são simples instrumentos, isto é, a mão de obra da produção" (2016, p. 105). Em seus escritos, examinam a luta dos reais produtores pelo controle na esfera dos empreendimentos econômicos, dando espaço para a luta dos trabalhadores no processo que conduziu à Revolução Russa e a análise do trabalho associado no capitalismo. Os autores destacam que o trabalho associado tem como característica inerente ser uma cooperação para si e apontam que a ideia de produtores associados liga-se a um projeto de sociedade que prevê seu controle pelos trabalhadores. Portanto, na sociedade capitalista, veem o trabalho associado como 
dissidência desenvolvida pela classe trabalhadora - uma espécie de anomalia social.

Intitulada "Cooperação e agroecologia: uma introdução crítica sobre o modelo de Ater", a discussão proposta por Alex Kawakami e Liziane Lucia de Souza encerra o segundo bloco de textos. Os autores destacam a ineficiência do sistema produtivo hegemônico, baseado em usos de agrotóxicos e transgênicos e no desmatamento, e propõem arranjar caminhos para garantir a soberania alimentar de todos. Em meio a muitos enfoques possíveis, privilegiam as alternativas emancipatórias de fortalecimento e desenvolvimento da produção agroecológica, via cooperação. De forma crítica, versam sobre a Assistência e Extensão Rural (Ater) e tratam do método Camponês a Camponês (CAC). Criado na Guatemala, na década de 1970, o método CAC trata-se de possibilidade de cooperação entre os trabalhadores visando a sua autonomia, uma vez que pretende a independência com relação à Ater oficial.

$\mathrm{Na}$ terceira parte do livro, os autores tratam sobre a produção destrutiva e a agroecologia, apresentando interessantes reflexões conceituais e teóricas, estudos de caso e vinculações da temática com a questão ambiental e a sustentabilidade. Henrique Novaes, Laís Santos, João Henrique Pires e Antonio Claudio Fuzer tecem análise crítica sobre o fetiche da revolução verde e desvelam a concentração fundiária, o controle das corporações sobre sementes, adubos e agrotóxicos e seus efeitos maléficos em termos socioambientais. Segundo esses autores, a concepção de agroecologia do MST é político-econômica e cultural, indo muito além de produção orgânica e preservação do meio ambiente. Assim, a agroecologia é entendida "como parte da estratégia de luta e de enfrentamento ao agronegócio, à exploração dos trabalhadores e à depredação da natureza"; ela inclui, além da produção de alimentos, o "cuidado e a defesa da vida, a consciência política e organizacional" (2016, p. 216). A união entre teoria e prática agroecológicas tem sido um dos desafios das escolas de agroecologia do MST, auxiliando também a pensar a tão necessária reforma agrária.

Será que essas experiências em agroecologia - vividas pelos agricultores camponeses nos assentamentos e acampamentos de reforma agrária do MST - se traduzem em diferentes formas de relação com o trabalho e a natureza? Esse questionamento serviu de mote às investigações de Wilson Mazalla Neto, apresentadas no capítulo "Agroecologia e crítica da alienação". Para o autor, a agroecologia atua

[...] tencionando a pretensa imutabilidade das relações sociais e a impossibilidade de transformar as expressões da opressão, dominação e exploração presentes na modernidade (2016, p. 238).

Mazalla Neto identifica significativos elementos de enfrentamento da alienação dentre agricultores camponeses envolvidos com a agroecologia.

As reflexões de Francisco Roberto Caporal e José Antonio Costabeber colaboram, sobretudo, no debate conceitual sobre agroecologia. Eles partem da apresentação do que ela não é e do senso comum a respeito para, então, discutir com profundidade a questão. Ao final de sua exposição, alertam sobre im- 
portantes aspectos em se tratando de desenvolvimento rural e agricultura sustentável.

O texto de Dominique Guhur, por sua vez, apresenta a abordagem materialista dialética para pensar a questão ambiental ou ecológica. Ainda que de forma geral, ela investiga o funcionamento do capitalismo, destacando os efeitos da concorrência, seja no interior de cada ramo de produção ou entre ramos de produção diferentes, sobre o ambiente. A autora reconhece que não há um conceito único e consensual da agroecologia e destaca que ela não se trata de contraposição à evolução das forças produtivas, mas, sim, de escolha de tecnologias mais pertinentes. Sob o olhar da Via Campesina, a agroecologia é entendida como o

[...] modo de vida, no interior dos antagonismos, das contradições e dos conflitos com a forma hegemônica do capital sobre o campo - o agronegócio - e a humanidade planetariamente - o capitalismo (2016, p. 296).

Para a autora, a agroecologia se coloca na tentativa de construção de "uma sociedade de produtores livremente associados com a sustentação de toda a Vida" (2016, p. 297), como sujeitos históricos autônomos.

A última parte do livro agrega reflexões acerca de trabalho, gênero e juventude no campo. Rogério Fernandes Macedo analisa a mundialização do capital em suas relações com a crise estrutural do capital a partir dos anos 1970 e os consequentes ataques à força de trabalho: aumento da alienação, do emprego precário/parcial/temporário e do desemprego. Processos esses que, hoje, ganham notável impulso com as políticas neoliberais e desafiam a classe trabalhado- ra para organização, conscientização e luta. Do sistema do capital, Macedo destaca, também, um viés pouco discutido e demasiado destrutivo aos trabalhadores: o complexo da fome e da degradação dos hábitos alimentares. Matam lentamente, tirando o vigor dos indivíduos que,

[...] a cada refeição debilitante, estão ocultamente famintos de nutrientes ausentes, embora abarrotados de calorias e de substâncias pouco nutritivas ou, de tudo, tóxicas (2016, p. 313).

Essa desnutrição em massa é apresentada em números pelo autor.

Em seguida, Antonio Thomaz Junior aplica-se à categoria trabalho para pensá-la como elemento fundante para a compreensão do campo no Brasil. Sobretudo, interessam-lhe as mudanças nas formas de organização do processo de trabalho, expressas na precarização, informalização, desproletarização, etc. Segundo Thomaz Junior, os efeitos desse metabolismo societário do capital são promotores de

[...] profundos rearranjos territoriais e consequentemente, redefinições locacionais do domínio espacial e mexem profundamente com o universo simbólico e com a subjetividade da classe-que-vive-do-trabalho (2016, p. 332).

Assim, a reestruturação produtiva do capital gera desdobramentos espaciais e territoriais que rebatem sobre o mundo do trabalho, seja no campo, seja nos centros urbanos.

O trabalho e o protagonismo das mulheres rurais são tema de Bruna Mendes de Vasconcellos, que destaca sua atuação enquanto sujeitos políticos. É fato que as de- 
sigualdades sociais no campo brasileiro não atingem a todos da mesma forma. Desde os anos 1980, tem sido constante a luta das mulheres rurais contra a invisibilidade de seu trabalho e contra sua maior vulnerabilidade econômica e social. Nesse sentido, o trabalho associado e a agroecologia tornam-se projetos políticos que visam à autonomia econômica das mulheres, resultando, igualmente, em sua maior inserção política e na transformação de um imaginário social patriarcal. Com propriedade, a autora resgata o histórico de organização dos movimentos das mulheres trabalhadoras rurais, suas principais conquistas e os desafios da atualidade na busca por maior igualdade de gênero.

$O$ último artigo do livro trata das perspectivas e dos desafios para a juventude rural no contexto da agricultura familiar brasileira. Os autores examinam e problematizam a relação trabalho-família-produção, os conceitos de juventude, seus dilemas em permanecer ou não no campo e o papel das políticas públicas nesse contexto. De forma geral, há um desperdício do potencial dos jovens para o desenvolvimento do país, na medida em que vivenciam precária inserção no mercado de trabalho e exclusão social, não contam com suficientes políticas públicas, que lhes permitam acessar a terra, o crédito, a assistência técnica e a extensão rural. Situação que obstaculiza sua permanência no campo, sua autonomia bem como a qualidade de vida e de trabalho. Assim, fica evidente que é imprescindível, para o nosso desenvolvimento, reconhecer a relevância dos jovens como sujeitos políticos e cidadãos e ampliar as oportunidades e as perspectivas no espaço rural.
Direcionada a um público amplo, de leigos a especialistas de diversas áreas, Questão agrária, cooperação e agroecologia contribui, com argumentos claros, para uma importante reflexão acerca do tempo presente e de caminhos necessários e possíveis para a transformação social. As substanciais análises apresentadas pelos autores informam, esclarecem e provocam o leitor não apenas ao pensamento crítico, mas também à ação, tendo por horizonte a superação do capitalismo e da exploração desmedida da natureza e a emancipação da classe trabalhadora. É uma contribuição que se torna ainda mais relevante em tempos de avanço feroz do capital e de sérios ataques aos direitos sociais e trabalhistas. Há, ainda, um segundo volume da obra Questão agrária, cooperação e agroecologia, não comentado nestas páginas, que igualmente merece leitura.

\section{Referências}

NOVAES, Henrique; MAZIN, Ângelo Diogo; SANTOS, Laís (Org.). Questão agrária, cooperação e agroecologia. 2. ed. São Paulo: Outras Expressões, 2016. v. 1. 